\title{
Characteristic and performance of polysulphone-polyethylene glycol synthetic hybrid membrane in water purification system
}

\author{
Shahrul bin Jainudin ${ }^{1}$, Sharifah Abdullah ${ }^{1}$, Jurina Jaafar ${ }^{1}$, Zulhafizal Othman $^{3 *}$, Aminuddin Baki $^{2}$ \\ and Nurhidayah Hamzah ${ }^{1}$ \\ Faculty of Civil Engineering, Universiti Teknologi MARA, Shah Alam, Selangor Malaysia ${ }^{1}$ \\ Envirab Services, GPO Shah Alam, Selangor Malaysia ${ }^{2}$ \\ Faculty of Civil Engineering, Universiti Teknologi MARA Pahang, Pahang Malaysia ${ }^{3}$
}

Received: 12-November-2020; Revised: 15-March-2021; Accepted: 17-March-2021

(C)2021 Shahrul Bin Jainudin et al. This is an open access article distributed under the Creative Commons Attribution (CC BY) License, which permits unrestricted use, distribution, and reproduction in any medium, provided the original work is properly cited.

\begin{abstract}
In the fast-changing modern world, fabrication of membrane is one of the rising technologies. Although membrane fabrication is mostly used in the separation process, most people are still unaware of the capabilities of the membrane sheet could give a strong impact on the finishing product outcome. Membrane fouling where the accumulation of particles in the pores and surfaces of the hybrid membrane one of the major highlights in membrane fabrication process. This research is mainly focused on identifying the optimum formulation of hybrid polymer membrane fabrications. This study also to investigate the characteristic, morphology and performance of the optimum hybrid polymer membrane. Fabrications of Flat sheet asymmetric polymeric synthetic hybrid membrane with the combinations of Polysulfone (PSF), Polyethylene Glycol (PEG) and 1-methyl-2-pyrrolidone (NMD) as the solvent has been conducted with five (5) different formulations. In order to test the characteristics of the synthetic hybrid membranes from membrane sheet for five (5) different formulation have undergone Tensile Strength Test, Permeate Flux Test, NaCl Rejection Test and FourierTransform Infrared (FTIR) Spectroscopy. The optimum performance of the synthetic hybrid membrane 3 (M3) has been obtained. Membrane (M3) was further analyzed with Scanning Electron Microscopy (SEM) to determine its morphology. The hybrid membrane (M3) was tested in a wastewater filtration system to determine the performance of the particles removal capabilities. The produced formulation membrane (M3) has created a Microporous membrane in $0.35-0.37 \mu m$ pore size, which was suitable to filter out particles in the wastewater.
\end{abstract}

\section{Keywords}

Synthetic hybrid membrane, Polysulfone (PSF), Polyethylene glycol (PEG) and 1-methyl-2-pyrrolidone (NMD), Wastewater filtration.

\section{Introduction}

The consumption of drinking water that are using one of the most common membrane processes, which is Reverse Osmosis (RO) that remove any contaminants or impurities to produce a clean drinking water [1]. Besides that, in the manufacturing industries frequently apply the separation process using membrane as a part of their systems structure [2]. The same author also stated that one of the common usages are including the elimination of bacteria and microorganism in producing lactose-free diary product. Furthermore, membrane separation process also widely used in medical and pharmaceutical field, such as dialysis where excess fluid, salt and waste will be removed from the patient bloodstream.

*Author for correspondence 484
These are just some of the usage and applications of membrane in our daily life which could be improved by further improvisation in the fabrication and production $[3,4]$.

The fabrication of membrane has a similar purpose, which is to build a separation mechanism process to obtain the desired results. Besides that, the structure of membrane is essentially made of permeable layer that act as the separation barrier system [5]. These barriers play important rule to allows certain molecules or particles to enter and exits the permeable layer. Furthermore, membrane classifications are depending on the size of the pore structure. The smaller and denser the morphology of the membrane, the harder for any particle to pass through it [5]. 
In order to create the movement of the feed through the membrane layer, it will be consistently driven either by applying pressure, concentration, temperature or even using electrical potential components in order to ensure a smooth constant flow passing through the membrane layer. While the filtered substance that failed to pass through the membrane will be retained at the surface of the membrane. The feed that has successfully pass through were usually known as permeate or flux [6].

While most of the common process of membrane separation process were mainly to remove unenviable chemicals such as metallic chemical elements, or physical substances such as suspended solid. Some other benefits of using membrane are as a separation medium is to effectively remove ions, dissolved minerals and gasses existed in the feed [7]. With the proper productions of membrane process, the filtration process of these impurities could be done effectively and produce treated potable water. This research is mainly focused in identifying the optimum formulation of hybrid polymer membrane fabrications and to investigate the characteristic, morphology and performance of the optimum hybrid polymer membrane. Some of the limitations of this research are the availability of the materials which is Polysulfone (PSF), Polyvinylpyrrolidone (PVP) and 1-Methyl-2-pyrrolidinone (NMP) that were used in the hybrid polymer membrane formulation. The availability of Ultra-Pure Water in order to test the Flux and Salt Rejection also one of the main highlights in this study. Lastly, the wastewater that has been collected will be determined the efficiency and functionality of the hybrid polymer membrane.

\section{Literature review}

\section{A.Membrane technology in our daily lives}

Membrane separation process is one of the technologies that has been widely used in our daily life [8]. This advanced technology that has been integrated into our portable equipment which helps to simplify our daily live activities. As an example, in residential and commercial area, most of the residence nowadays has acquired a water purifier system in their houses. This is one of the major usages of membrane separation process where it will soften and filter the water from impurities such as suspended solid, dissolved chemical, ions and other impurities and makes the filtered water suitable to be drink directly. In addition, Jiang et al stated that one of the most common usage of membrane separation process today are the integration of membrane filter in air conditioning equipment. Membrane separation process also has become one of the important parts in air conditioning nowadays. For instance, in Malaysia where we are having a tropical weather with average of $29^{\circ} \mathrm{C}$ all year around where air conditioner is required to chill and reduce the indoor air temperature for thermal comfort. And besides cooling the surrounding air, most of air conditioning system has been installed with membrane filter that able to filter out and capture dust, pollen, mites, smokes and other foreign particle in the air that might be harmful to people with sensitive health conditions [5]. By having these machines installed, the indoor air quality has been improved and provide a better air ventilation and circulation for the residence.

\section{B. Introduction to synthetic hybrid membrane}

Ariono et al. [9] According to isopropanol and ethanol (IBE) (2017), membrane is typically known as a sheet with a specific thickness that act as semipermeable layer that acts as a selective barrier. This fabricated layer will only allow some molecules or particles to pass through and retain any other impurities which helps to regulates the movement from different phases in a controlled enclosed mechanism. Initially, there are two (2) types of membrane, which is Biological Membrane and Synthetic Membrane [10, 11]. Biological Membrane or usually known as Biomembrane are a naturally formed membrane that is become an essential part in living things. These Biomembrane structure were made of living cells that will acts as the separation layer. In comparison to Synthetic Membrane, an artificial membrane where it is fabricated through a series of research and innovation which specifically made for the purpose of industrial or laboratory activity.

In the recent time, Synthetic Hybrid Membrane is well known and studied by various researcher to improve and innovate from the previous research due to its useful beneficial features [9]. Synthetic Hybrid Membrane are one of the types of membrane that uses the combination of several materials in a specific formulation in order to create a new kind of membrane morphology and function [12]. Some of the common materials used from organic or inorganic materials such as metal or ceramic, homogeneous films (polymers), heterogeneous solids. Due to the manual fabrications, it is easy to do modifications and adjustments to the membrane structure and produce it according to a diverse different usage and applications. Harun et al. [3] also agreed that the changes that can be made to the fabrication of the synthetic hybrid membrane will creates a better 
morphology and simultaneously could enhance the efficiency of the membrane itself rather than just a semipermeable layer that could filter particle in and out in a system [3].

\section{Fabrication of synthetic hybrid membrane}

In this research, three (3) main materials used in the fabrication of synthetic hybrid membrane which consist of two (2) types of polymer solvent which is Polysulfone (PSF) and Polyethylene Glycol (PEG). While for the solvent 1-Methyl-2-pyrrolidinone (NMP) were used.

\section{Hybrid Polymer}

Polymer were mostly used due to the toughness and strength properties against corrosion and pressure. Different polymer has different features and advantages, thus by combining them into a new hybrid polymer will subsequently improve their morphology and strength during the membrane separation process [13].

\section{a) Polysulphone (PSF)}

Polysulphone or usually known as PSF are a part of thermoplastic polymers where they possess a high stability and toughness against temperature. They contain the subunit aryl-SO2-aryl, the defining feature of which is the sulfone group and usually used for the replacements in polycarbonates. PSF could retains their rigid and strong properties between $100{ }^{\circ} \mathrm{C}$ and $150{ }^{\circ} \mathrm{C}$ which also can be use under high pressure due to their high compaction resistance. The ease in manufacturing is one of the reason where PSF were widely used in the industry such as wastewater recovery, food production and gas separation [14].

\section{b) Polyethylene Glycol (PEG)}

Polyethylene glycol (PEG) is a polyether compound which also known as polyethylene oxide (PEO) or polyoxyethylene (POE) depending on its molecular weight. PEG is widely used in the industry such as manufacturing or medical industry. PEG are prepared by polymerization of ethylene oxide and are commercially available over a wide range of molecular weights from $300 \mathrm{~g} / \mathrm{mol}$ to $10,000,000$ $\mathrm{g} / \mathrm{mol}[15]$.

\section{c) 1-Methyl-2-pyrrolidinone (NMP)}

1-Methyl-2-Pyrrolidone or known as NPM is an organic compound and a type of solvent where usually added in the membrane formulation process. Due to the excellent solvency properties, NMP is widely used along with the fabrications of polymeric membranes. It is also widely used in textile industry as an addition in surface treatment and pharmaceutical field [16]. Table 1 is Below comparison between previous studies.

Table 1 Comparison between previous studies

\begin{tabular}{clclc}
\hline No. & \multicolumn{1}{c}{ Researchers } & Membranes & \multicolumn{1}{c}{ Findings } & Applications \\
\hline 1. & $\begin{array}{l}\text { Bailon and Berthold } \\
{[15]}\end{array}$ & Nano & $\begin{array}{l}\text { Polyethylene glycol (PEG)-conjugated proteins belong to a } \\
\text { new class of biomolecules that are neither proteins nor } \\
\text { polymers, but which are hybrids of the two }\end{array}$ & $\begin{array}{c}\text { Protein } \\
\text { filtration }\end{array}$ \\
\hline 2. & Rikabi et al. [16] & Nano & Polysulphone has high thermal resistance $\left(150-170^{\circ} \mathrm{C}\right)$ & Filtration \\
\hline 3. & Souza and Quadri [17] & Nano & $\begin{array}{l}\text { Addition of nanoparticles may increase the cross-linking } \\
\text { center for the polymer and reduce the tendency of the } \\
\text { polymer for self-organization of polymer-particle adhesion }\end{array}$ & - \\
\hline 4. & Mohamad et al. 18] & Micro & $\begin{array}{l}\text { Main disadvantage of polysulfone and polyethersulfone is } \\
\text { their hydrophobicity, which leads to an apparent tendency to } \\
\text { interact strongly with a variety of solutes and thus makes } \\
\text { them prone to fouling }\end{array}$ & Filtration \\
\hline 5. & Yunos et al.[19] & Nano & $\begin{array}{l}\text { Modification of membrane via improvement of membrane } \\
\text { structure, mechanical properties and performance }\end{array}$ & Filtration \\
\hline 6. & Rodríguez [13] & Nano & Membranes conductivity with water content capacity & $\begin{array}{l}\text { Fuel Cell } \\
\text { technologies }\end{array}$ \\
\hline
\end{tabular}

\section{Methodology \\ $\mathbf{1}^{\text {st }}$ Phase}

A. Fabrications Polysulphone-Poly Ethylene Glycol Synthetic Hybrid Membrane
By using Polysulphone (PSF $35000 \mathrm{MW}$ ) as the base polymer, Polyethylene Glycol (PEG $40000 \mathrm{MW}$ ) as the secondary polymer and 1-methyl-2-pyrrolidone (NMD) as the solvent, five (5) formulations of Polysulphone-Poly Ethylene Glycol Synthetic Hybrid 
Membrane have been conducted. The formulations were as shown as Table 2 below.

Table 2 Five (5) formulations of synthetic hybrid membrane

\begin{tabular}{llll}
\hline Membrane & PSF $(\boldsymbol{\%})$ & PEG(\%) & NMD(\%) \\
\hline M1 & 9.48 & 9.48 & 81.05 \\
\hline M2 & 11.37 & 7.58 & 81.05 \\
\hline M3 & 13.27 & 5.68 & 81.05 \\
\hline M4 & 15.16 & 3.79 & 81.05 \\
\hline M5 & 17.06 & 1.90 & 81.05 \\
\hline
\end{tabular}

\section{B. Dope preparation}

The dope preparation methodology was conducted as follows. All the materials were weighted according to Table 2, placed in a covered beaker for 24 hours. Afterwards, the mixing process was conducted with $400 \mathrm{rpm}, 55^{\circ} \mathrm{C}$ for six (6) hours. Next, it was poured into the capped bottles and kept in a ultrasonic bath

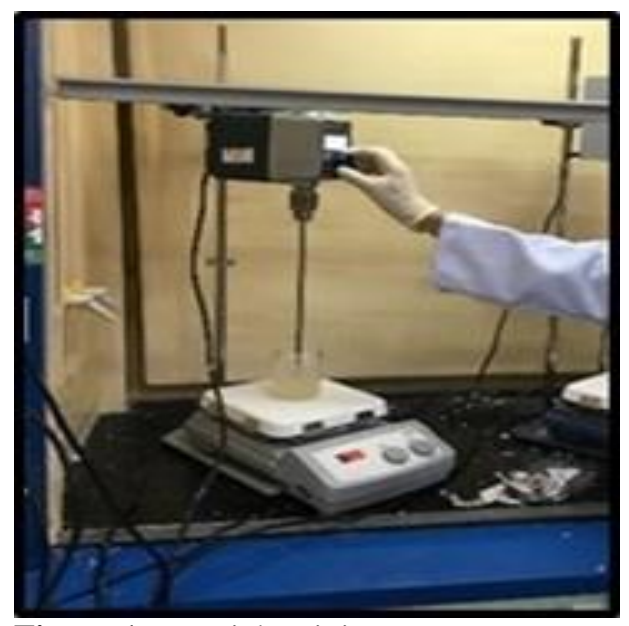

Figure 1 Materials mixing process

\section{C.Synthetic hybrid membrane casting}

The glass plate with the dope sheet layer were immersed directly into the water bath. The water bath which is in the room temperature at around $28{ }^{\circ} \mathrm{C}$ will caused the solution turned into a flat sheet membrane immediately. Next, it will be removed and the glass plate was cleaned for the next usage. This step were repeated for three (3) times to obtained three (3) sample of each formulation. The pneumatically controlled flat sheet membrane machine was used with a thickness of $250 \mu \mathrm{m}$. After the dope undergoes inversion phase with the water bath, it was left hang to dry for another 24 hours. for 48 hours to completely remove excess air bubbles. Then it was kept for another 24 hours. Figure 1 shows the mixing process of the materials and Figure 2 shows the solution that has been mixed according to the formulation in Table 2.

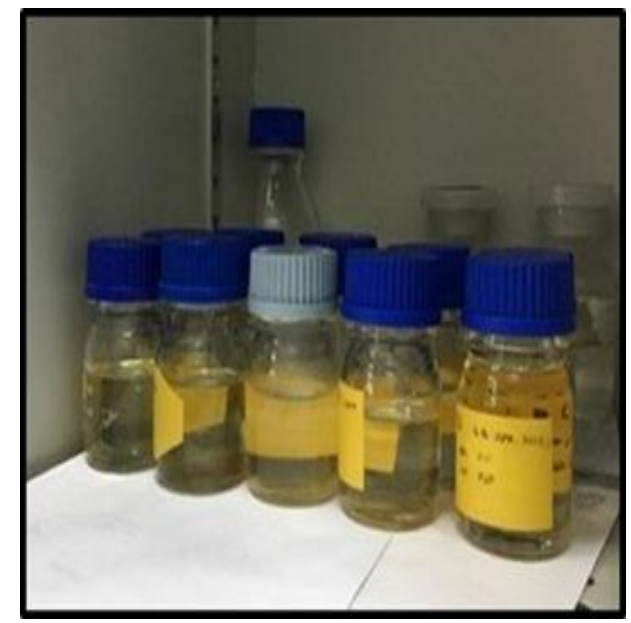

Figure 2 Completely mixed solution in bottles

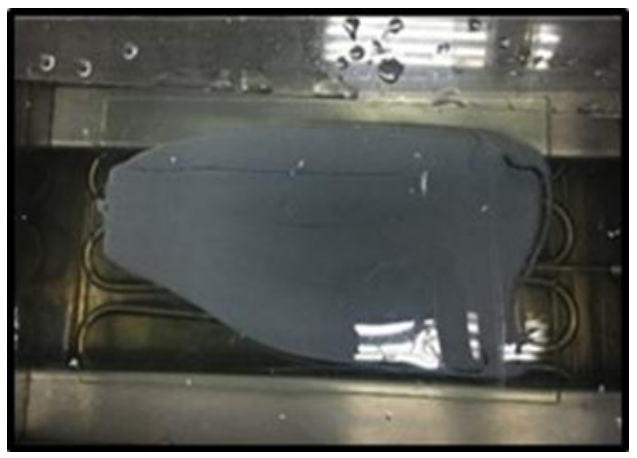

Figure 3 Dope layer phase immersion process 
$2^{\text {nd }}$ Phase

A.Characteristic analysis and testing

In this phase, there were four (4) testing conducted to determine and analyzed the characteristic of the synthetic hybrid membrane.

\section{Permeate Flux}

The membrane sheet was cut in a diameter of $7.5 \mathrm{~cm}$ and placed in the pump filtering valve. Pure Water was used along with the equipment. The volume and time were recorded. Equation 1 below was used to obtain the value of the permeate flux for each of the membrane sheet.

$J_{v}=\frac{Q_{P}(L)}{A\left(m^{2}\right) \times T(h r)}$

\section{NaCl Rejection}

Sodium Chloride $(\mathrm{NaCl})$ of $2000 \mathrm{mg} / \mathrm{L}$ and 5 Liter of Pure Water were used in this testing. The process was the same for Permeate Flux.The duration and volume were recorded. The solution before and after the testing was analyzed for Salinity, Conductivity, and Total Dissolved Solids.

\section{Fourier transform infrared spectroscopy (FTIR)}

The FTIR method uses infrared light to scan samples and observe the chemical properties. All the membrane sheet has undergone the FTIR analysis, which was conducted at the Laboratory of Applied Science, UiTM.

\section{Tensile strength test}

Dynamic Mechanical Analyzer (DMA) from Mettler Toledo (DMA 1) was used in this analysis. First the membrane samples were immersed in a water bath at room temperature for about 24 hours and were cut into a rectangular shape of $6 \mathrm{~mm}$ by $25 \mathrm{~mm}$. The test was performed at room temperature at a rate of 2 $\mathrm{N} / \mathrm{min}$. The results were obtained from the TOLEDO Software in the desktop

\section{$3^{\text {rd }}$ Phase}

A. Morphology and performance analysis In this phase, the morphology and performance of the membrane out of the five (5) formulations selected.

\section{SEM}

SEM Analysis was done at The Faculty of Dentistry at UiTM Sungai Buloh, Selangor. The selected membrane sheet was cut into rectangular shape and was coated with gold with SC7620 Mini Sputter Coater/Glow Discharge System from Quorum Technologies. After coating, the membrane was placed in the TM3000 Tabletop Scanning Electron Microscope and undergoes scanning process. The surface morphology images were shown on the computer by using the Hitachi TM3000 software.

\section{Wastewater Testing}

A water from the selected location has been obtained and the sampling process was following the standard MS ISO 5667-6:2014, "Guidance on sampling of rivers \& streams". Since the water depth of the lake is too great for wading, the water body is accessed from a bridge. By using a rope and bucket, the water sample of $500 \mathrm{ml}$ was retrieved. Six (6) water quality analysis was conducted, which is consist of:
a. $\mathrm{pH}$
b. Turbidity
c. Color
d. Total Suspended Solids
e. Chemical Oxygen Demand
f. Escherichia Coli

\section{Results and discussion}

\section{A. Tensile strength test}

From the Figure 4, M1 has the lowest value among all the membrane sheet with the stress value of 34.5 $\mathrm{kpa}$ at the 3.4 strain axis. It also has the lowest strain value which is 4.67 which shows it has the lowest tensile strength among all the membrane sheet which causing it to break during the permeate flux testing.

M3 has the highest strain value among all of the membrane sheets, which is $59.5 \mathrm{kPa}$ and the strain point of 4.7, which is slightly lower than [3]. It also exerts the same maximum strains at 6.15 . Among all of the membrane sheets, M3 definitely has the best stress strength. Comparing to M5 shows a slightly lower stress reading, which is at $57 \mathrm{kPa}$ at the strain reading of 4 . It is obvious that M5 has the highest durability among all of the membrane sheets. It is also shown the increase in amount of PEG percentage will greatly affect the strength of the synthetic hybrid membrane [6]. The results obtained is exactly similar to the pervious study. As mentioned in previous research, the higher the PEG dosage will weaken the mechanical properties of the membrane itself due to the high number of porosities.

To conclude, M3 and M5 have the best tensile stress. The different advantages M3 has the best stress loading capacity while M5 has the best durability. Both membranes also have the highest stress value comparing to others. 


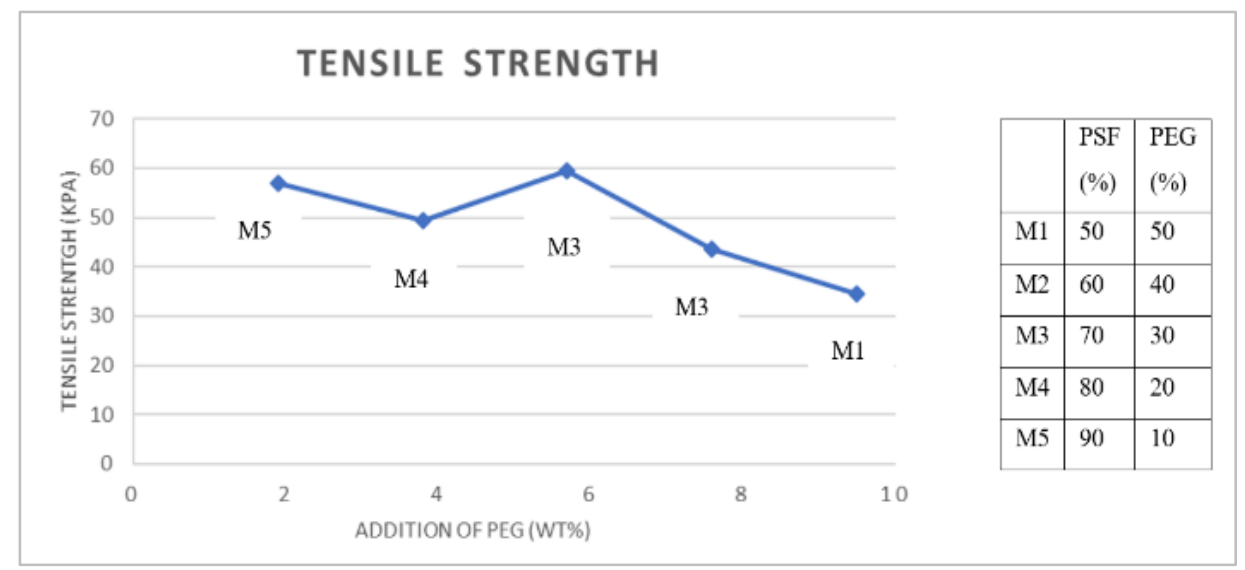

Figure 4 Tensile strength stress-strain graph

\section{B. Permeate flux}

Based on the results obtained in Figure 5, M1 could not withstand the constant pressure from the pump, which causing it to burst and no results were obtained. M3 shown a better flux performance comparing to all the membrane sheet. With permeate flux value of $34.53 \mathrm{~L} / \mathrm{m} 2 . \mathrm{hr}$, M3 is comparatively $28 \%$ much better than the second-best membrane, which is M5.

M3 shown the highest permeate flux value which is $34.53 \mathrm{~L} / \mathrm{m} 2 . \mathrm{hr}$ which has the addition of $5.68 \%$ PEG polymer to the formulation. This shows that the addition of $1 \%-8 \%$ of secondary polymer to the membrane formulation as suggested by [8] and [9] does give an optimum impact toward the permeate flux.
Based on previous research, [8] and [5] have obtained $27 \mathrm{~L} / \mathrm{m} 2$ and $80.80 \mathrm{~L} / \mathrm{m} 2$ respectively. There is slightly higher amount of permeate flux in [5] due to the PEG used were 400 in molecular weight. These studies underlined that the molecular weight plays an important role in determining the number of pores that will affect the output of the volume of permeate flux. The higher the molecular weight, the stronger the strength of the polymer and higher number of pores will be formed. For the permeate flux, most of the previous researcher such as $[5,6,10]$ have obtained a higher range of permeate flux up to $60-80$ L/m2.hr.

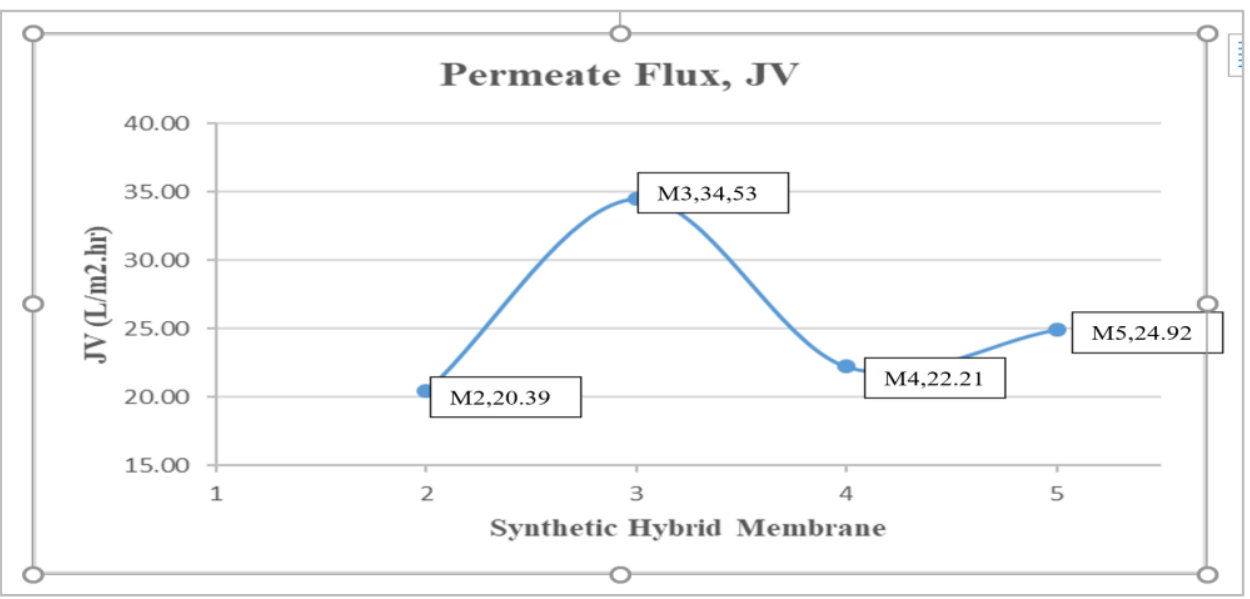

Figure 5 Permeate flux of synthetic hybrid membrane 
C. $\mathrm{NaCl}$ Rejection

\section{Salinity}

Based on Figure 6, it shows that M3, M4, and M5 have the lowest salinity level, which is 1.5 PSU. According to [9], by having an additional of $2 \%-8 \%$ PEG will be causing the pore to be increased and hence, the filtration of salt water will increase. While the Salinity level in M2 is slightly increase from the other membrane sheet. This is because the higher addition of PEG could negatively affect the performance of the membrane filtration as mentioned by [10].

As shown in Figure 6, it M3, M4 and M5 have a similar $\mathrm{NaCl}$ removal percentage, which is $11.8 \%$. While the lowest was M2, which is $5.9 \%$.

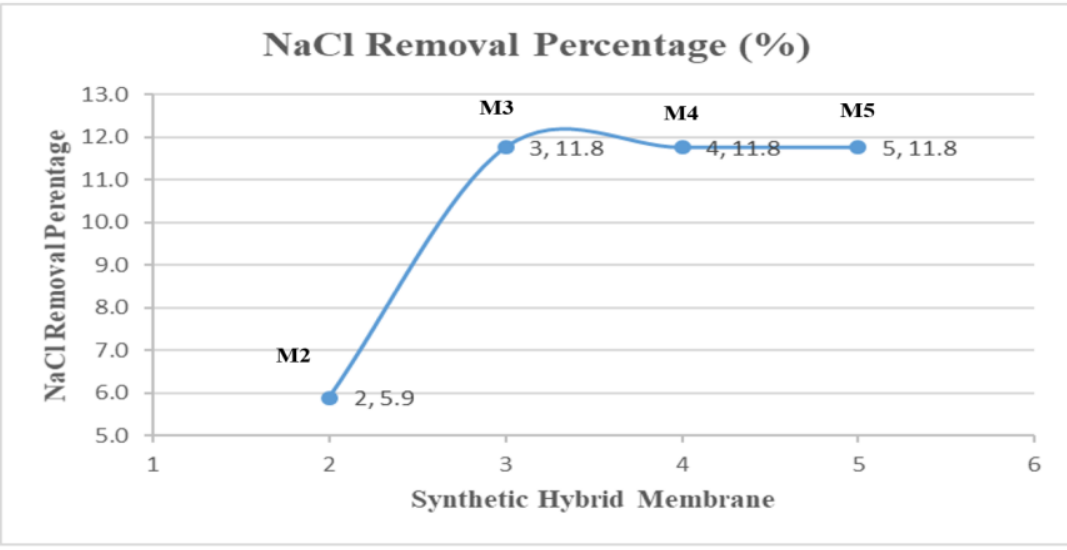

Figure $6 \mathrm{NaCl}$ removal percentage

\section{Conductivity}

Figure 7 shows the electricity conductivity ability of each membranes. Based on the data obtained, the membranes show a reduction of Salinity level from the unfiltered $3.3 \mathrm{~S} / \mathrm{m} \mathrm{NaCl}$ solution. M3 has the lowest conductivity which is $3.08 \mathrm{~S} / \mathrm{m}$. This shows that the M3 has the highest filtration of ions of salt content that affect the conductivity of the solution.
The higher the addition of PEG, the lower the conductivity level of the filtered feed [11]. This is generally due to the filtration uptake that cause by the increase in the size and number of pore size in the membrane sheet morphology. Higher addition will affect the permeability of the membrane. By having good permeability, the filtration rate could be slower.

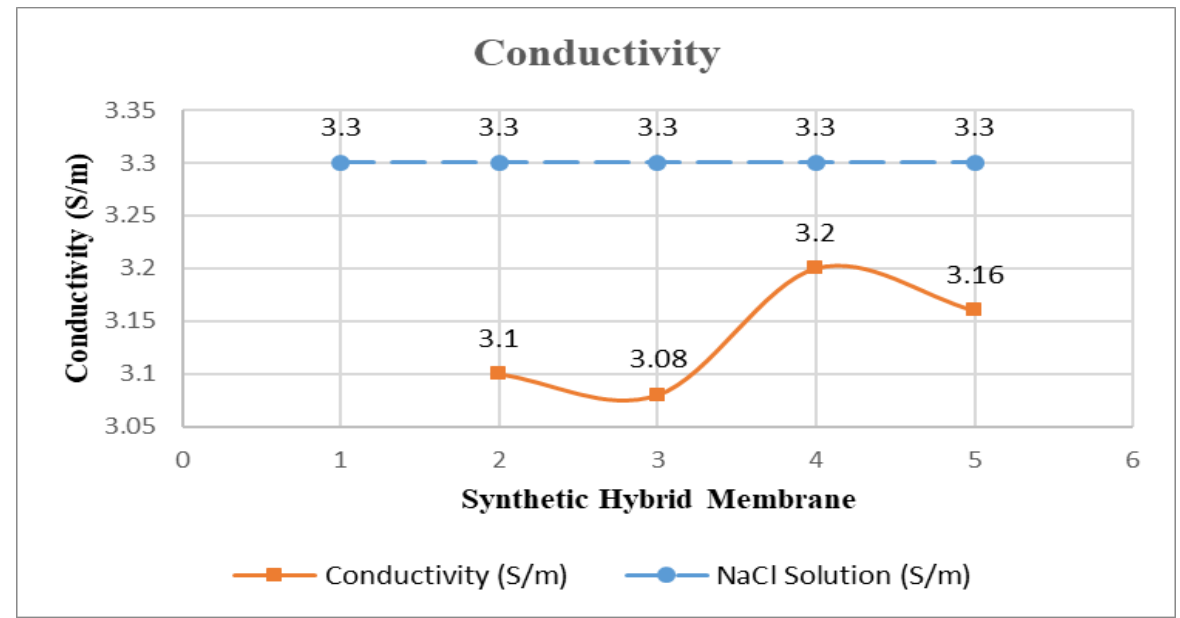

Figure 7 The conductivity level of the membrane 
Total dissolved solids

Based on Figure 8, the membranes show a reduction in the number of TDS. It is shown that M3 has the lowest TDS value, which is $1444 \mathrm{ppm}$. Comparing to the other 3 membranes, it shows that M3 is $6.4 \%$ better at TDS filtration. It is shown that the $5.68 \%$ of the PEG added to the membrane formulation can produced excellent number of pore sizes and improve permeability with a good filtration ability. A proper addition of PEG amount will cause an optimum filtration where the process will run smoothly according to the pore size produced [5].

\section{Overview of $\mathrm{NaCl}$ rejection}

As shown in Figure 9, the trend line shows that the Salinity and Conductivity were similar. This is because one of the parameters that affect the electrical conductivity level in a aqueous solution are due to the existence of salt [12]. The higher the salinity, the higher the conductivity level.
While for the Total Dissolved Solids (TDS), the trend lines show a slight declined pattern at M3 and continuously increase to M4 and slightly increased at M5. This shows that the filtration of TDS is the highest in M3, which can be related to the addition of secondary polymer PEG to a membrane formulation does greatly affect the filtration effect, but adding too much of it also could lower down the performance [3, $20]$.

The amount of PEG added to the formulation of synthetic hybrid membrane, the hydrophilicity will be improved simultaneously which causing an increase in water absorption for the stated membrane [11]. When the water absorption ability has been increased, this will be causing the permeability inside the membrane structure to be increased.

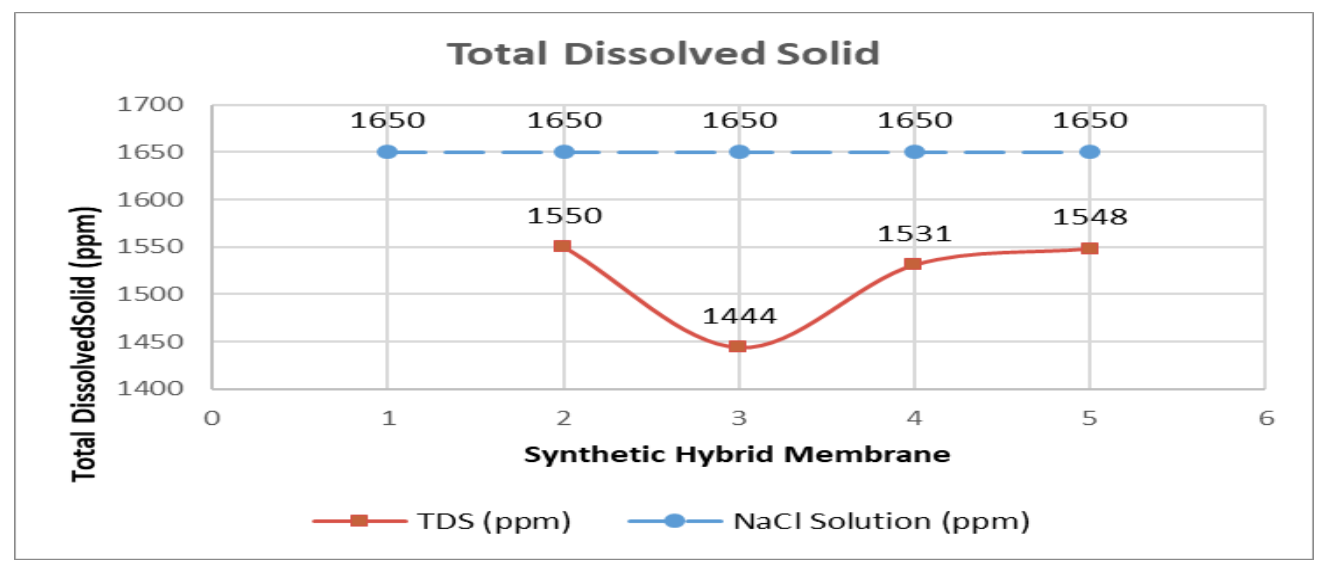

Figure 8 Tensile strength stress-strain graph

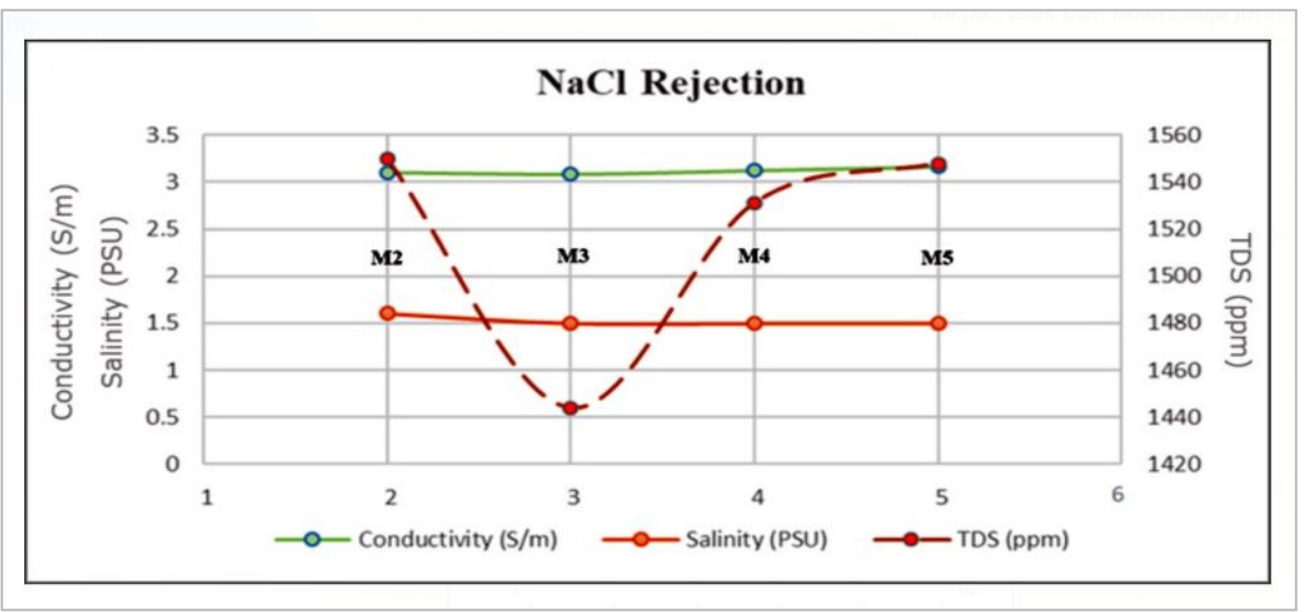

Figure 9 Tensile strength stress-strain graph 


\section{Fourier transform infrared spectroscopy (ftir)} FTIR analysis was conducted in order to determine the composition of all the synthetic hybrid membrane sheet. The results are shown in Figure 10. The membranes show C-N stretch at around 1020-1250 $\mathrm{cm}-1$ indicating a strong aliphatic amine absorption, in which membrane 3 (M3) has the highest wavelength $(1237.11 \mathrm{~cm}-1)$ and membrane 4 has the lowest $(1102.73 \mathrm{~cm}-1)$, this shift is caused by the presence of amide group from the NMP solvent [21, 22]. It can also be seen that these membranes are secondary aromatic with three $\mathrm{C}-\mathrm{H}$ "oop" bonds and about $2 \mathrm{C}-\mathrm{C}$ stretch rings.

Based on all the result obtained, M3 are the best optimum synthetic hybrid membrane. M3 has the highest strength, permeate flux and better salt rejection among all the five (5) synthetic hybrid membrane formulation. M3 with the formulation of that consist of $13.27 \%$ PSF, 5.68\% PEG and $81.05 \%$ NMD will be selected for the Scanning Electron Microscopy (SEM) analysis and wastewater filtration.

\section{Scanning electron microscope (SEM)}

As shown in the Figure 11, the cross section shows a homogenous and uniform structure. At magnification of $\mathrm{x} 250$, the top section of the membrane showed a dense layer and the below the dense layer, there was intermediate porous sub-layer and at the bottom, porous spongy support layers were identified.

The pore sizes in M3 (Figure 12) are $3.5 \mu \mathrm{m}-3.7$ $\mu \mathrm{m}$ and this membrane can be classified as Microporous Membrane. According to [3, 15, 16, 17], the surface pores with the sub-cavities are the main mechanism membrane layer in accommodating water. According to the previous researchers, due to the hydrophilicity characteristic of PEG the microporous surface formed also provide an excellent permeation, besides it is good in mechanical strength against corrosion and weathering against chemical.

To compare with the previous researchers such as [5, $16,17]$, the structure of membrane that had in the studies has shown more pores, shorter finger like structure but larger voids in it. This is because most of membrane used were using PEG400, which has a molecular weight of $400 \mathrm{MW}$. This type of PEG has less resistant to chemical and low viscosity [6]. These features could accommodate higher amount of water in the structure that could produce a better permeate flux.

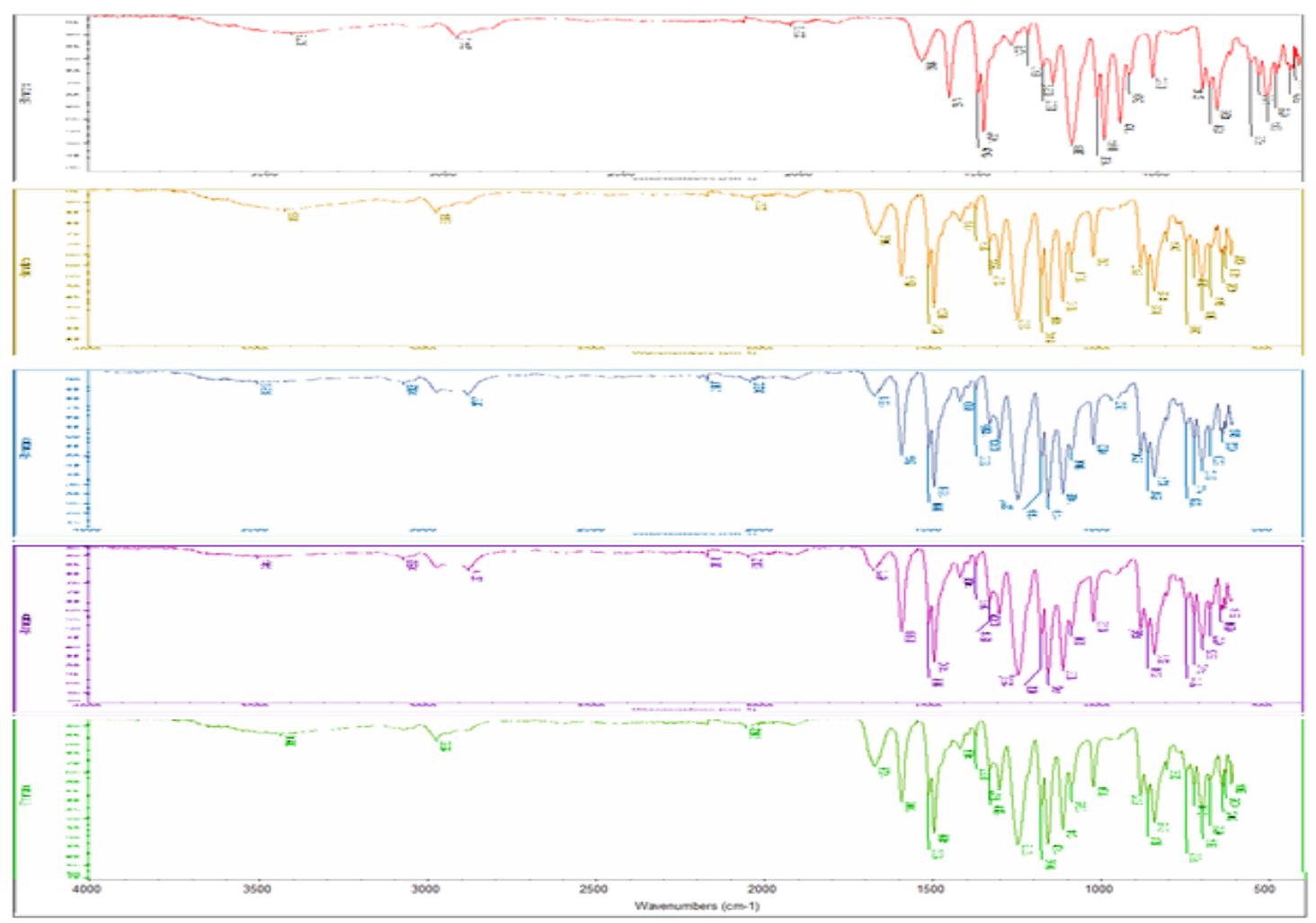

Figure 10 Fourier-transform infrared (FTIR) spectroscopy graph for all synthetic hybrid membrane 492 


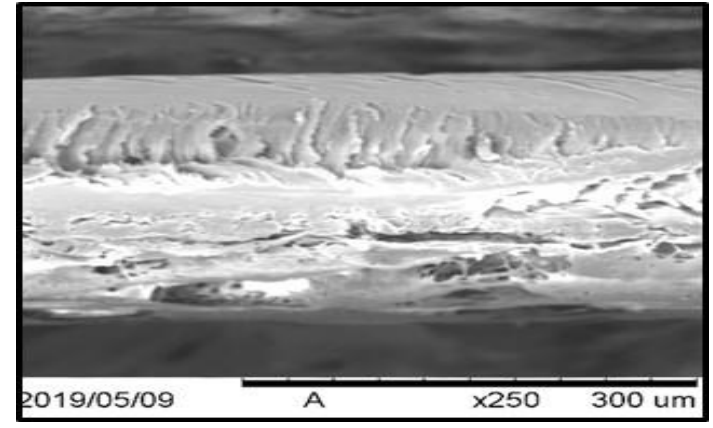

Figure 11 Cross section of synthetic hybrid membrane

\section{Wastewater filtration}

Based on Table 3, it is shown that the water quality parameter was decreasing from the Unfiltered sample to Filtered wastewater sample. The highest performance can be seen on the turbidity level which is $42.82 \%$. The second highest performance is the removal of TSS with $20.88 \%$. Both of this percentage shows that this microporous synthetic hybrid membrane area able to efficiently filter the particles that existed in the wastewater. The membrane also can remove color about $11.5 \%$.

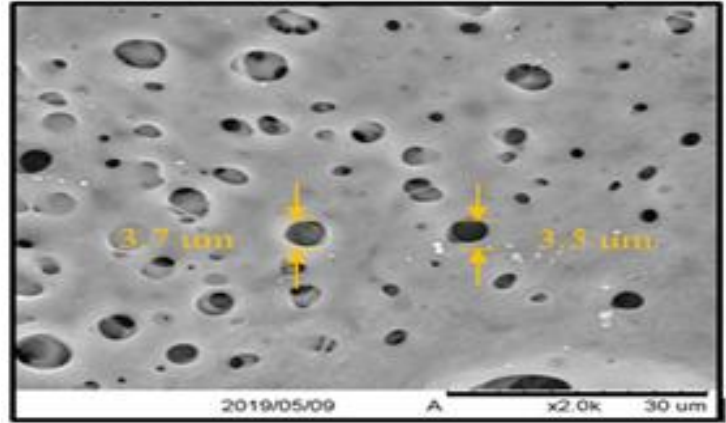

Figure 12 The Synthetic Hybrid Membrane Surface

While for TDS and salinity, there are only slight decrease in the filtration changes. This is because these parameters require Nano sized membrane to efficiently altered their existence in an aqueous body $[8,2]$. For the Chemical parameter, there are also slight change in COD that the micro porous membrane able to filter. While for the E-Coli need further analysis due to the value is out of range complications. Comparing to the Malaysia National Water Quality Standards (MNWQS), the filtered water can be classified as Class II(A).

Table 3 The filtration performance and water class of synthetic hybrid membrane

\begin{tabular}{lllll}
\hline Characteristic & $\begin{array}{l}\text { Unfiltered } \\
\text { wastewater }\end{array}$ & Filtered wastewater & Performance (\%) & NWQSM class II (A) \\
\hline Turbidity (NTU) & 131 & 74.9 & 42.82 & 50 \\
\hline Color (Pt/Co) & 529 & 468 & 11.53 & 150 \\
\hline Conductivity (S/m) & 160.8 & 157.2 & 2.24 & 1000 \\
\hline TSS (ppm) & 91 & 72 & 20.88 & 50 \\
\hline TDS (ppm) & 80.4 & 78.6 & 2.4 & 1000 \\
\hline COD (mg/L) & 21 & 18 & 14.29 & 1 \\
\hline Salonity (PSU) & 0.1 & 0.1 & 0.00 & $6-9$ \\
\hline pH & 7.14 & 7.42 & -3.92 & 3 \\
\hline E-coli $(\mathbf{c f u} / \mathbf{1 0 0 m L )}$ & $>2419.6$ & $>2419.6$ & - & \\
\hline
\end{tabular}

\section{Limitation of the research}

Some of the limitations of this research are the availability of the materials which is Polysulfone (PSF), Polyvinylpyrrolidone (PVP) and 1-Methyl-2pyrrolidinone (NMP) that were used in the hybrid polymer membrane formulation. Besides, there are three limitation of parameters analyzed on this research includes Physical Analysis ( $\mathrm{pH}$, turbidity, color, suspended solid), Chemical analysis (COD) and Biological analysis (BOD).

\section{Conclusion}

In this research, five formulations of synthetic hybrid membranes have been conducted by using Polysulphone as the base polymer with the addition of Polyethylene Glycol as the secondary polymer. Among those five (5) membranes formulations, the 493 best optimum synthetic hybrid membrane formulation for both of the polymer is made of $13.27 \%$ PSf, $5.68 \%$ PEG and $81.05 \%$ of NMD as the solvent.

The optimum synthetic hybrid membrane M3 was able to withstand $59.5 \mathrm{kpa}$ stress with strain of 4.7 . M3 shown a better flux performance comparing to other the membranes sheet with permeate flux value of $34.53 \mathrm{~L} / \mathrm{m} 2 . \mathrm{hr}$. The produced formulation M3 has created a Microporous membrane with $0.35-0.37$ $\mu \mathrm{m}$ pore size which was suitable to filter out particles in the wastewater. The formulation of membrane M3 can be further studied so that the permeate flux can be increased to improve the synthetic hybrid membrane performance. It is suggested for the future research that the usage of additives in the formulation 
could be considered in order to increase the performance and characteristic of the membrane sheet. Some of the characteristic that could be improve are Permeate Flux and lower the susceptibility towards membrane fouling.

\section{Acknowledgment}

None.

\section{Conflicts of interest}

The authors have no conflicts of interest to declare.

\section{References}

[1] https://www.nst.com.my/business/2019/06/494417/co way-invest-more-malaysia. Accessed 22 June 2019.

[2] Jiang S, Li Y, Ladewig BP. A review of reverse osmosis membrane fouling and control strategies. Science of the Total Environment. 2017; 595:567-83.

[3] Harun Z, Yunos MZ, NAZRI K, YUSOF MF, Lau WJ, Salleh WN. Optimization and characterization of polysulfone membranes made of zinc oxide, polyethylene glycol and eugenol as additives. Journal of Engineering Science and Technology. 2016; 11(7):1001-15

[4] Wang Q, Wu X, Chen J, Li W, Zhang H, Wang J. Ultrathin and stable organic-inorganic lamellar composite membrane for high-performance organic solvent nanofiltration. Chemical Engineering Science. 2020; 228:116002.

[5] Pulyalina A, Polotskaya G, Rostovtseva V, Pientka Z, Toikka A. Improved hydrogen separation using hybrid membrane composed of nanodiamonds and P84 copolyimide. Polymers. 2018; 10(8):1-12.

[6] Ma Y, Shi F, Ma J, Wu M, Zhang J, Gao C. Effect of PEG additive on the morphology and performance of polysulfone ultrafiltration membranes. Desalination. 2011; 272(1-3):51-8.

[7] Aslam M, Lee PH, Kim J. Analysis of membrane fouling with porous membrane filters by microbial suspensions for autotrophic nitrogen transformations. Separation and Purification Technology. 2015; 146:284-93.

[8] Schäfer AI, Fane AG, Waite TD. Cost factors and chemical pretreatment effects in the membrane filtration of waters containing natural organic matter. Water Research. 2001; 35(6):1509-17.

[9] Ariono D, Prabandari D, Wulandari R, Wenten IG. Preparation and characterization of polysulfone/PEG heterogeneous ion exchange membrane for reverse electrodialysis (RED). In journal of physics: conference series 2017 (pp. 1-6). IOP Publishing.

[10] Melone L, Giorno L, Brunetti A, Barbieri G. Analysis of membrane unit performance in presence of wet CO2-containing mixtures. Chemical Engineering Research and Design. 2020; 153:721-7.
[11] Zhao J, Ren L, Chen QB, Li P, Wang J. Fabrication of cation exchange membrane with excellent stabilities for electrodialysis: a study of effective sulfonation degree in ion transport mechanism. Journal of Membrane Science. 2020; 615:118539.

[12] Jamalludin MR, Harun Z, Hubadillah SK, Othman $\mathrm{MH}$, Kamarudin NH, Yunos MZ, et al. Optimization of polysulfone/graphene oxide/polyethylene glycol/triaminopyrimidine by using response surface methodology. In IOP conference series: materials science and engineering 2018 (p. 1-7). IOP Publishing.

[13] Rodríguez J, Rojas N, Sánchez-Molina M, Rodriguez LG, Campana R, Rodríguez L. Hybrid membranes based in Nafion-metallic oxides: performance evaluations. Chemical Engineering Transactions. 2016; 47:415-20.

[14] Hou D, Li T, Chen X, He S, Dai J, Mofid SA, et al. Hydrophobic nanostructured wood membrane for thermally efficient distillation. Science Advances. 2019; 5(8):1-8.

[15] Bailon P, Berthold W. Polyethylene glycol-conjugated pharmaceutical proteins. Pharmaceutical Science \& Technology Today. 1998; 1(8):352-6.

[16] Rikabi AA, Nechifor AC, Mohammed TJ, Oprea O, Miron AR, Segarceanu M, et al. Nano composite membrane on polysulphone matrix. REVISTA DE CHIMIE. 2016; 67(8):1489-97.

[17] Souza VC, Quadri MG. Organic-inorganic hybrid membranes in separation processes: a 10-year review. Brazilian Journal of Chemical Engineering. 2013; 30(4):683-700.

[18] Mohamad SH, Abdullah HZ, Idris MI, Harun Z, Ismail AF, Yunos MZ, et al. Influence of polyethylene glycol (PEG) additive on performance polysulfone (PSf) and polyethersulfone (PES) membrane. 2013.

[19] Yunos MZ, Harun Z, Basri H, Ismail AF. Studies on fouling by natural organic matter (NOM) on polysulfone membranes: effect of polyethylene glycol (PEG). Desalination. 2014; 333(1):36-44.

[20] Aris KM, Ramli SU, Othman ZU, Jaafar JU. Evaluation of ammonia-nitrogen removal by ultrasonic irradiation in synthetic solution using response surface methodology. In key engineering materials 2019 (pp. 108-17). Trans Tech Publications Ltd.

[21] Abdullah R, Ishak CF, Kadir WR, Bakar RA. Characterization and feasibility assessment of recycled paper mill sludges for land application in relation to the environment. International journal of environmental research and public health. 2015; 12(8):9314-29.

[22] Sinha A, Biswas P, Sarkar S, Bora U, Purkait MK. Separation of chloride and sulphate ions from nanofiltration rejected wastewater of steel industry. Journal of Water Process Engineering. 2020; $33: 101108$ 


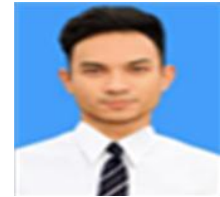

Shahrul Bin Jainudin is in Faculty of Civil Engineering, Universiti Teknologi MARA Shah Alam Research. His research areas are Bioremediation and Membrane Filtration.

Email: sharifah.abdullah@uitm.edu.my

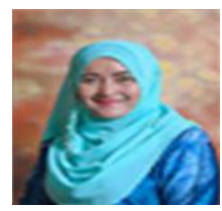

Sharifah Abdullah is a Senior Lecturer in the Faculty of Civil Engineering, Universiti Teknologi MARA Shah Alam Research. Her research areas are Bioremediation and Membrane Filtration.

Email: zulhafizal445@uitm.edu.my

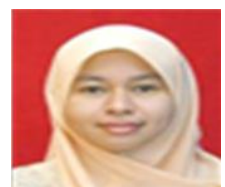

Jurina Jaafar is a Senior Lecturer in the Faculty of Civil Engineering, Universiti Teknologi MARA Shah Alam Research. Her research areas are Bioremediation and Membrane Filtration.

Email: nurhidayah0527@uitm.edu.my

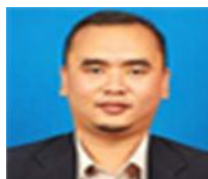

Zulhafizal Othman is a Senior Lecturer in the Faculty of Civil Engineering, Universiti Teknologi MARA Pahang Branch. His research areas are Water Quality, and Micropollutant Engineering.

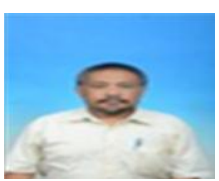

Aminuddin Baki is in Envirab Services. His research areas are Water Quality, Water and Wastewater Treatment.

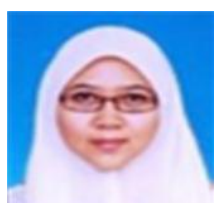

Nurhidayah Hamzah is a Senior Lecturer, Faculty of Civil Engineering, Universiti Teknologi MARA Shah Alam. Her research areas are Bioremediation, Water and Wastewater Treatment.

Email:aminbaki@msn.com 